\title{
Ocorrência de má oclusão em pacientes pediátricos atendidos em uma clínica integrada de odontologia
}

Occurrence of malocclusion in pediatric patients seen at an integrated dental clinic

Natanael Ramos dos Santos ${ }^{1}$; Roberto Carlos Carvalho Cerqueira ${ }^{1}$; Kaliane Rocha Soledade $^{3}$; Larissa Rolim Borges-Paluch ${ }^{4 *}$

${ }^{1}$ Faculdade Maria Milza - FAMAM, BR-101, Governador Mangabeira - BA, Brasil, 44350000, natanramos@live.com; robertocarlosc13@ hotmail.com

${ }^{3 *}$ Faculdade Maria Milza - FAMAM, Programa de Pós-Graduação em Desenvolvimento Regional e Meio Ambiente, BR-101, Governador Mangabeira - BA, Brasil, 44350-000, krsoledade@gmail.com

4*Faculdade Maria Milza - FAMAM, Programa de Pós-Graduação em Desenvolvimento Regional e Meio Ambiente, BR-101, Governador Mangabeira - BA, Brasil, 44350-000, larissapaluch@gmail.com ORCID: https://orcid.org/0000-0002-1810-0902

\section{Resumo}

As más oclusões são classificadas como um dos maiores problemas bucais pela Organização Mundial de Saúde. Nesse sentido, a pesquisa teve como objetivos investigar os tipos de más oclusões mais frequentes em pacientes pediátricos atendidos em uma clínica-escola no Recôncavo da Bahia e averiguar os hábitos bucais deletérios presentes nestes pacientes. A pesquisa aborda o tema de forma epidemiológica transversa, documental e com abordagem quantitativa. Os dados obtidos foram originados de prontuários odontológicos oriundos de pacientes pediátricos atendidos na clínica odontológica. Dos 180 prontuários avaliados constatou-se que a maioria dos pacientes pertence ao sexo masculino (58\%), com idade entre 5 e 8 anos (78\%) e predominância étnico-racial de faiodermas (40\%) No que se refere as más oclusões, foi evidenciado que 13,8\% apresentaram más Oclusões Verticais, 36,1\% Más Oclusões Anteroposteriores e 5\% Má Oclusão Transversal. Em relação às más oclusões anteroposteriores, foi observado que $16,7 \%$ dos pacientes amostrados apresentavam má oclusão de classe I, 13,9\% dos pacientes apresentavam de classe II e 5,5\% dos pacientes de classe III segundo classificação de Angle. Evidencia-se a necessidade da adoção de medidas para a implementação de ortodontia interceptativa e realização de procedimentos preventivos para evitar o agravamento das más oclusões. 
Palavras-chave: má oclusão, prontuários, odontopediatria.

\begin{abstract}
Abtsract
Malocclusions are classified as one of the biggest oral problems by the World Health Organization. In this sense, the research aimed to investigate the types of malocclusions most frequent in pediatric patients treated at a school clinic in Recôncavo da Bahia and to investigate habits deleterious oral diseases present in these patients. The research addresses the theme in a transversal, documentary and epidemiological way with a quantitative approach. The data obtained came from dental records from pediatric patients seen at the dental clinic. Of the 180 medical records evaluated, it was found that the majority of patients are male (58\%), aged between 5 and 8 years (78\%) and ethnic-racial predominance of phaderoderms (40\%) Regarding malocclusions, it was evidenced that 13.8\% had bad Vertical Occlusions, $36.1 \%$ Bad Anteroposterior Occlusions and 5\% Bad Transverse Occlusion. Regarding anteroposterior malocclusions, it was observed that $16.7 \%$ of the sampled patients had class I malocclusion, $13.9 \%$ of the patients had class II and $5.5 \%$ of class III patients according to Angle's classification. The need to adopt measures to implement interceptive orthodontics and preventive procedures to prevent the worsening of malocclusions is evident.
\end{abstract}

Keywords: malocclusion, medical records, pediatric dentistry

\title{
1.Introdução
}

$\mathrm{Na}$ região da cavidade bucal há ocorrência de eventos sucessivos para o desenvolvimento da oclusão, que pode ser dividido em três períodos distintos: a dentição decídua, que vai do nascimento até o período anterior a erupção dos primeiros dentes permanentes, que ocorre entre o período dos 5 aos 6 anos de idade; a dentição mista, que se inicia por volta dos 5 aos 6 anos de idade e perdura até aos 12 anos, podendo ir até os 13 anos de idade, já a dentição permanente dar-se início com a esfoliação do último dente decíduo por volta dos 12 anos de idade perdurando pelo resto da vida (Souki, 2016).

No desenvolvimento da arcada dentária podem ocorrer alterações quebrando a harmonia da oclusão, trazendo prejuízos pela falta de conformidade, sendo denominadas más oclusões. Atualmente o número de indivíduos atingidos por más oclusões é elevado, com prevalência em uma a cada quatro pessoas. Dentre os fatores desencadeadores desta anormalidade estão: a evolução humana, hábitos alimentares e sociais, e a miscigenação étnica. Guardo, em 1953, classificou as más oclusões em causas hereditárias e congênitas, gerais, locais e hábitos bucais (Almeida, 2013). 
Dentre os fatores pré-natais a hereditariedade é um dos principais desencadeadores da má oclusão, pois a mesma influencia no crescimento e desenvolvimento. Por exemplo, um indivíduo pode herdar de sua mãe a forma dos dentes e os maxilares de seu pai, podendo gerar uma forma não harmoniosa. Um dos fatores genéticos que também influencia no desenvolvimento das más oclusões é a miscigenação racial, pesquisadores observaram que em grupos étnicos homogêneos a prevalência de más oclusões é menor, enquanto que em grupos heterogêneos este número aumenta exponencialmente (Almeida et al., 2011).

Um dos fatores gerais que contribui para a má oclusão é uma alimentação inadequada, pois a mesma pode provocar alterações no desenvolvimento ósseo e dentário. Adicionalmente, uma alimentação rica em sacarose associada à higienização precária pode provocar a doença cárie, que elava a destruição do tecido dentário. Dentre os fatores locais temos a perda prematura dos dentes decíduos provocando a perda de equilíbrio da oclusão distalizando os anteriores, mesializando os posteriores e extruindo os antagonistas da área desdentada (Abrão, 2014).

O tecido ósseo é um dos conteúdos minerais mais densos do corpo humano, mas é susceptível a força mais suave, se a mesma for constante. A sucção de chupeta e a sucção digital promove uma alteração similar, causando abertura na oclusão no local onde se interpõe. Porém, a sucção de chupeta produz efeitos menos deletérios que a digital, e, muitas vezes é induzida pelos pais a fim de acalentar a criança inquieta. Os hábitos bucais deletérios devem receber merecida atenção dos odontólogos, pois geralmente nos hábitos que se estendem além do terceiro ano de vida da criança não ocorre o processo de correção espontânea (Tomita, 2000).

A Organização Mundial de Saúde designa as más oclusões como o terceiro problema de saúde pública em odontologia e causa multifatorial (OMS, 1991). Dentre as principais causas destacam-se os hábitos deletérios e as alterações congênitas. Ambos podem gerar distúrbios oclusais relacionados à estética, função, fonação, mastigação e deglutição, além de incômodo na vinculação interpessoal e autoconfiança (Vilain et al., 2016).

Dentre as más oclusões observadas em crianças de 5 a 12 anos de idade estão: as classificações de Angle I, II e III, denominadas más oclusões sagitais ou anteroposteriores; a sobremordida e a mordida aberta anterior e/ou posterior, que são más oclusões verticais; 
mordida cruzada posterior unilateral ou bilateral, que são anomalias oclusais transversais (Morais et al., 2016).

Edward Angle propôs que o primeiro molar superior ocupava uma posição estável em relação ao inferior e que as desarmonias anteroposteriores eram consequências do arco inferior, classificando as más oclusões em três categorias que se diferenciam da oclusão normal. A primeira classificação (Angle I) consiste na cúspide mesiovestibular ocluindo no suco vestibular central do primeiro molar inferior. Geralmente está acompanhado de alguma discrepância anterior, e dentre as classificações é a que tem melhor estabilidade funcional, proporcionando ao indivíduo um perfil reto. Na maioria das vezes, este é decorrente de fatores hereditários, alterações musculares, maus hábitos, anomalia de numeração dentaria, tamanho das unidades, alteração no crescimento e desenvolvimento dos maxilares (Cervantes et al., 2011).

A classe II caracteriza-se pela cúspide mesiovestibular que oclui mesialmente do suco vestibular central do primeiro molar inferior, sendo a má oclusão mais comum em caucasianos. Esta oclusão pode ser dentaria ou esquelética como uma prognatismo maxilar, retrusão mandibular ou associação de ambos. Existem dois tipos de más oclusões classe II: a divisão 1 e a divisão 2, as mesmas apresentam subdivisões quando exibidas unilateralmente que consistem em subdivisão direita e subdivisão esquerda (Nogueira, 2014).

Ainda segundo esse autor a classe II divisão 1 é a mais frequente, nesta divisão comumente nota-se o ressalto dos incisivos superiores provocando um aumento no overjet demonstrando uma face mais convexa, diferente da classe I que normalmente apresenta uma musculatura balanceada. Nesta má oclusão, nota-se uma musculatura mais incompetente com o lábio superior hipotônico, deglutição atípica. A classe II divisão 2, exibe uma retroinclinação dos incisivos centrais superiores e proinclinação dos incisivos laterais superiores sem mudanças estruturais esqueléticas exacerbadas, e uma curva de spee mais exacerbada no arco inferior, não apresentando problemas acentuados na musculatura.

A má oclusão classe III caracteriza-se por apresentar uma mesioclusão esquelética e/ou dentária da arcada inferior, devido a cúspide mesiovestibular repousar distalmente do suco vestibular central do primeiro molar inferior. Os casos podem variar desde uma mordida com 
contato topo a topo a uma mordida cruzada anterior, portanto, apresentando diversas anomalias variando em sua etiologia, prognóstico e tratamento (Guedes-Pinto, 2010).

A classe III pode ser funcional quando a mandíbula se encontra em uma relação normal, porém deslocada para frente, com os dentes inferiores anteriores vestibularizados e os superiores localizam-se posterior a estes. Pode ser esquelética em três situações: a primeira com a maxila normal, estando com a mandíbula anômala e tendo seu tamanho maior que o habitual; a segunda com a maxila em retrusão com os dentes superiores anteriores cobertos pelos inferiores. Na terceira situação pode apresentar a maxila e a mandibular com tamanho anormal, podendo exibir a mordida aberta, mordida cruzada e os dentes anteriores apinhados (Cervantes et al., 2011).

A mordida aberta é caracterizada pela ausência local de oclusão, originado por anomalias no desenvolvimento e/ou hábitos bucais deletérios, trazendo um comprometimento estético e funcional. A mesma pode ser de origem dentária ou esquelética, estando comumente localizada na região anterior, mas também pode acometer a região posterior. Para um bom desenvolvimento da oclusão é necessário uma adequada homeostasia muscular, pois, o osso onde estão inseridos os dentes configura-se num tecido plástico submisso a distorção quando há forças constantemente aplicadas, especialmente da musculatura que o circunda. Outro fator que provoca a quebra desta homeostasia são os hábitos deletérios como sucção digital, chupeta, desvio funcional da língua e dos lábios e a respiração bucal (Domann et al., 2016).

Sobremordida ou mordida profunda ocorre quando há um transpasse vertical excessivo dos dentes anteriores superiores sobre os inferiores provocando um aumento no overbite. Nos indivíduos que apresentam esta anomalia é possível observar clinicamente uma redução no terço inferior da face tornando-o mais braquicefálico e um perfil convexo. A mordida profunda pode ser dentária quando os incisivos se apresentam fora de suas bases ósseas, podendo até apresentar uma classe II de Angle; dentoesquelética quando apresenta alterações no desenvolvimento dentoalveolar. A origem da má oclusão pode ser ocasionada pelo adiantamento do maxilar e/ou retração mandibular, apresentando retroinclinação dos dentes anteriores; esquelético quando a um excesso no desenvolvimento do maxilar e/ou retrusão mandibular e existem poucos contatos dos dentes anteriores (Martins, 2016). 
Á mordida cruzada é uma má oclusão de variação transversal que pode acometer todo o arco dentário ou apenas um hemiarco. Na observação clínica temos o cruzamento na direção da linha média pelos dentes do arco superior, que passam a ocluir lingualmente em relação aos dentes inferiores. A mordida cruzada pode ser desenvolvida pela projeção da língua durante a fonação e deglutição, não estando tocando no palato duro em repulso, mas mantendo-se no assoalho, além da presença de respiração bucal e deglutição atípica (Piaia et al., 2016).

Para o tratamento desses problemas deve-se adotar medidas que busquem uma oclusão funcional sem sacrificar a estética facial. E, para se obter um tratamento adequado é necessário um diagnóstico eficiente e que possa orientar para uma melhor conduta terapêutica para o caso apresentado. Deve-se considerar dois aspectos de fundamental importância no diagnóstico: o olhar clínico, e o traçado cefalométrico, que permite conhecer amplamente as estruturas envolvidas, medi-las, descrevê-las e estudar suas relações (Olguín Vargas \& Yáñez Ocampo, 2016).

Nesse sentido, a pesquisa teve como objetivo investigar os tipos de más oclusões mais frequentes em pacientes pediátricos atendidos em uma clínica-escola no Recôncavo da Bahia e averiguar os hábitos bucais deletérios presentes nestes pacientes.

\section{Material e Métodos}

Trata-se de uma pesquisa epidemiológica transversal, documental e de abordagem quantitativa.

A pesquisa teve como cenário uma clínica-escola pertencente a uma Faculdade de Odontologia sediada no Recôncavo da Bahia. A clínica oferece serviços odontológicos nas especialidades de dentística, odontopediatria, endodontia, periodontia, prótese, cirurgia e radiologia.

As informações para a pesquisa foram extraídas de prontuários clínicos pertencentes a pacientes pediátricos. Os critérios de inclusão foram a realização de tratamento odontológico entre janeiro/2017 e junho/2018 e idade entre 5 e 12 anos. Os de exclusão foram grafia ilegível no prontuário e tratamento odontológico em andamento.

Realizou-se primeiramente a triagem dos prontuários odontológicos de acordo com os 
critérios pré-estabelecidos, efetuando-se o registro em uma ficha controle criada em planilha do programa Microsoft Office Excel. Foram anotados o registro oclusal e hábitos deletérios dos 180 pacientes pediátricos selecionados.

Os dados utilizados foram referentes às variáveis: sociodemográficas, comportamentais e odontológico dos pacientes, além do registro oclusal e hábitos bucais deletérios. As informações foram apresentados por meio de frequências absoluta e relativa, além do cálculo de média aritmética simples nas tabelas e figura.

O presente projeto possui aprovação do Comitê de Ética em Pesquisa, no 3.070.823, CAAE 04216218.4.0000.5025, e atentou a todos os princípios éticos da Resolução n ${ }^{\circ}$ 466/12 do Conselho Nacional de Saúde.

\section{Resultados e discussão}

Dos 180 prontuários avaliados pode-se constatar que a maioria os indivíduos que compõem o grupo de pacientes pediátricos atendidos na clínica-escola pertencem ao sexo masculino (57,8\%). A predominância étnico racial $^{1}$ foi de declarados faiodermas (40\%) e em 51 prontuários $(28,3 \%)$ não havia registro de cor/raça. A maioria dos pacientes $(77,6 \%)$ estava na faixa etária entre 5 e 8 anos (Tabela 1).

Tabela 1. Frequências absoluta $(\mathrm{N})$ e relativa (\%) referente ao perfil demográfico dos prontuários de pacientes pediátricos atendidos em Clínica-Escola. 2018.

\begin{tabular}{l|cc|ccc}
\hline \multicolumn{1}{c|}{ PERFIL } & \multicolumn{1}{c|}{$\mathrm{N}^{\circ}(\boldsymbol{\%})$} & PERFIL & $\mathrm{N}^{\circ}$ & $(\%)$ \\
\hline Sexo & & & Idade (em anos) & & \\
Masculino & 104 & $(57,8)$ & 5 & 35 & $(19,4)$ \\
Feminino & 76 & $(42,2)$ & 6 & 36 & $(20,0)$ \\
Cor/Raça & & & 7 & 32 & $(17,7)$ \\
Leucoderma & 19 & $(10,5)$ & 8 & 37 & $(20,5)$ \\
Faioderma & 72 & $(40,0)$ & 9 & 10 & $(05,5)$ \\
\hline
\end{tabular}

\footnotetext{
${ }^{1}$ A nomenclatura adotada para a identificação da raça/cor da pele na área médico-legal foi baseada em caracteres fenotípicos de Roquette-Pinto (1933), levando em conta, sobretudo, a cor da pele e cujas denominações sao: melanoderma (melanodermos) para pretos; leucoderma (leucodermos) para brancos; faioderma (phaiodermos) para pardos; xantoderma (xanthodermos) para amarelo
} 


\begin{tabular}{l|cc|ccc} 
Melanoderma & 38 & $(21,1)$ & 10 & 13 & $(07,2)$ \\
Não declarado & 51 & $(28,3)$ & 11 & 13 & $(07,2)$ \\
& & & 12 & 04 & $(02,2)$ \\
\hline Total & 180 & $(100)$ & & 180 & $(100)$ \\
\hline
\end{tabular}

Os dados da pesquisa em relação ao sexo estão de acordo com a estimativa da população pertencente ao município, pois segundo dados do Instituto Brasileiro de Geografia e Estatística - IBGE, a maior parte dos indivíduos entre 5 a 14 anos de idade pertence ao sexo masculino (IBGE, 2017).

A cor de pele predominante nos pacientes pediátricos presentes nos prontuários verificados foi de faiodermas e melanodermas, totalizando $85 \%$ das crianças. Essa informação diverge parcialmente dos dados observados pelo IBGE, que cita que a predominância étnico racial na Bahia é de faiodermas (59\%), seguido de leucodermas (22\%) e melanodermas (17\%) (IBGE, 2011).

Esta mesma distribuição também foi verificada por Frazão, Rodrigues e Pereira (2015) em São Luís, no Maranhão, que avaliou 502 escolares da rede pública e observou predominância de faiodermas $(76 \%)$ seguido de leucodermas $(17 \%)$.

\section{a. Registro Oclusal dos Pacientes Pediátricos}

As informações referentes ao registro oclusal dos pacientes demonstram que dos 180 prontuários analisados $69,4 \%$ das crianças atendidas estão no período de dentição mista e 31,1\% apresentavam hábitos bucais deletérios.

Em relação às más oclusões anteroposteriores 16,7\% dos pacientes amostrados apresentavam má oclusão de classe I, 13,9\% dos pacientes apresentavam de classe II e 5,5\% dos pacientes de classe III segundo classificação de Angle.

Pode-se observar pelos dados obtidos na pesquisa que em relação às más oclusões verticais 5,5\% dos pacientes apresentavam sobremordida e 8,3\% mordida aberta. Também se evidenciou no estudo que, referente à má oclusão transversal, 5,0\% dos pacientes apresentava mordida cruzada posterior (Tabela 2). 
Tabela 2. Frequências absoluta $(\mathrm{N})$ e relativa $(\%)$ referentes ao registro oclusal dos prontuários de pacientes pediátricos atendidos em Clínica-Escola. 2018.

\begin{tabular}{|c|c|c|c|}
\hline EXAME OCLUSAL & $\mathbf{N}^{\circ}(\%)$ & EXAME OCLUSAL & $\mathrm{N}^{\circ}(\%)$ \\
\hline Dentição mista & $125 \quad(69,4)$ & \multicolumn{2}{|c|}{ Más Oclusões Anteroposteriores } \\
\hline Hábitos bucais deletérios & $56(31,1)$ & Classe I de Angle & $30(16,7)$ \\
\hline \multicolumn{2}{|l|}{ Más Oclusões Verticais } & Classe II de Angle & $25(13,9)$ \\
\hline Mordida aberta & $15(08,3)$ & Classe III de Angle & $10(05,5)$ \\
\hline \multirow[t]{2}{*}{ Sobremordida } & \multirow[t]{2}{*}{$10(05,5)$} & \multicolumn{2}{|l|}{ Má Oclusão Transversal } \\
\hline & & Cruzada posterior* & $09(05,0)$ \\
\hline
\end{tabular}

* mordida cruzada posterior.

De acordo com Felício et al. (2010) crianças na faixa etária de 5 a 8 anos estão passando pelo estágio inicial da dentição mista, o primeiro período transitório, que percorre da erupção do primeiro molar permanente até a substituição do incisivo lateral decíduo pelo permanente, estando mais susceptíveis a alterações oclusais. Nesse período o indivíduo apresenta diversas mudanças fisiológicas intra e extra oral, neste estágio qualquer interferência intrínseca ou extrínseca, pode acarretar em severos danos orais.

No que se refere as más oclusões sagitais, na pesquisa verificou-se a predominância de indivíduos que apresentavam má oclusão classe I, seguidos pelos que apresentavam classe II e classe III. Dados semelhantes foram observados por Almeida et al. (2011) que evidenciaram a prevalência de más oclusões em 3.466 crianças com idade de 7 a 12 anos, sendo que 55,25\% exibiram uma predominância em relação ao molar Classe I, 38\% de Classe II e 6,75\% de Classe III de Angle.

Porém, estes dados divergem de Frazão et al., (2015) que realizaram uma pesquisa amostrando 502 crianças, e relataram que dentre as anomalias anteroposteriores encontradas a classe I foi a mais presente (59\%), seguido pela classe III (29\%) e a classe II (12\%).

Estudo realizado pelo Ministério da Saúde em 2010, que avaliou todas as capitais e diversos municípios de todas as regiões do Brasil, concluiu que a mordida cruzada anterior esteve presente em apenas cerca de 3,0\% de crianças com 5 anos de idade, sem variação 
significativa entre as regiões. A maior variação foi observada com relação à presença de mordida aberta anterior, sendo que a região Norte apresentou menor prevalência $(5,9 \%)$ do que a Região Nordeste (12,3\%), a Região Sul (18,9\%) e o Brasil (12,1\%). No país, assim como em todas as regiões, a prevalência de mordida cruzada posterior não variou de maneira significativa, sendo que a menor prevalência desse agravo foi encontrada na Região Norte $(10,1 \%)$ (Brasil, 2012).

Morais et al. (2016) exibiram dados diferentes e constataram que, dos 617 escolares avaliados em Vazante, Minas Gerais, 17\% das crianças entre 7 e 12 anos apresentavam mordida profunda e $4 \%$ exibiam mordida aberta

Em relação a má oclusão transversal dados semelhantes ao presente estudo também foram encontrados por Boeck et al. (2012). Esses autores avaliaram a prevalência de más oclusões em 1.446 discentes entre 5 a 12 anos de escolas municipais de Araraquara-SP e e observaram a presença de mordida cruzada posterior em $12,72 \%$ dos estudantes. Sua ocorrência é determinada por hábitos bucais deletérios como sucção digital, sucção de chupeta respiração bucal. Este tipo de má oclusão, na maioria das vezes, tende a não se autocorrigir ou sofrer mudanças com o passar da idade, havendo necessidade da intervenção ortodôntica.

No que se refere à quantidade de indivíduos que apresentavam más oclusões foi registrado que 37,8\% dos usuários pediátricos apresentavam apenas uma e 7,2\% duas más oclusões. E em relação aos hábitos bucais deletérios encontrados nos prontuários, 21,1\% apresentavam apenas um hábito e 9,5\% dois hábitos bucais deletérios (Tabela 3).

Tabela 3. Frequências absoluta $(\mathrm{N})$ e relativa $(\%)$ referentes a quantidade de indivíduos relacionados aos registros oclusais de más oclusões e hábitos bucais deletérios presentes nos prontuários de pacientes pediátricos atendidos em Clínica-Escola. 2018.

\begin{tabular}{|c|cc|ccc|}
\hline \multicolumn{2}{|c|}{ EXAME OCLUSAL } & \multicolumn{2}{|c}{$\mathbf{N}^{\circ}(\boldsymbol{\%})$} & EXAME OCLUSAL & $\mathbf{N}^{\circ}(\boldsymbol{\%})$ \\
\hline Más Oclusões & & & Quantidade de Hábitos Bucais Deletérios \\
1 & 68 & $(37,8)$ & 1 & 38 & $(21,1)$ \\
2 & 13 & $(07,2)$ & 2 & 17 & $(9,5)$ \\
3 & 02 & $(01,1)$ & 3 & 01 & $(0,5)$ \\
\hline
\end{tabular}




\begin{tabular}{l|c|cc}
\multicolumn{1}{c|}{ Não há* } & $97(53,9)$ & Não há* & $124(68,9)$ \\
\hline Total & $180(100)$ & & $180(100)$ \\
\hline
\end{tabular}

*Não foram evidenciados.

Como descrito na tabela 3 , foi evidenciado que a maioria dos pacientes apresentavam apenas um hábito bucal. O mesmo resultado foi observado por Vasconcelos et al. (2009) em sua pesquisa referente a hábitos bucais deletérios em 970 crianças de Recife-PE, que constatou que $47,1 \%$ possuíam apenas um tipo de hábito, $12,1 \%$ dois hábitos e 1,6\% três hábitos simultaneamente.

Relacionado ao gênero, registrou-se que, as más oclusões foram predominantes em crianças do gênero masculino (48\%) do que do feminino (41\%) (gráfico 1)

Gráfico 1. Frequências relativa (\%) referentes a má oclusão por sexo nos prontuários de pacientes pediátricos atendidos em Clínica-Escola. 2018.

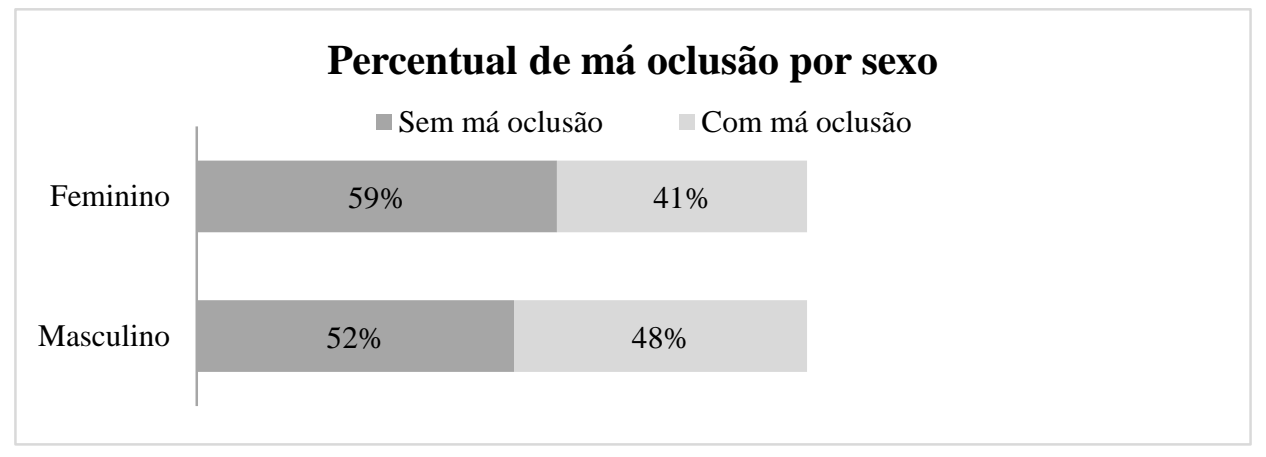

Estudo realizado por Boeck et al. (2012), em que avaliou a prevalência de más oclusões em alunos das escolas municipais de Araraquara-SP, cujos os participantes da pesquisa tinham idades entre 5 a 12 anos, sendo um total de 1.446 estudantes, encontrou números similares do atual estudo neste quesito, pois, registrou que a má oclusão estava presente em $81,34 \%$ das crianças do sexo feminino, enquanto que enquanto que $79,07 \%$ dos escolares do sexo masculino apresentavam anomalias oclusais.

\section{b. Identificação dos Hábitos Bucais Deletérios}

Relacionado aos hábitos bucais deletérios observados, 3,3\% dos pacientes apresentavam sucção digital (chupar o dedo), 1,7\% dos pacientes exibiam sucção de chupeta, $5,5 \%$ dos 
indivíduos presentes nos prontuários faziam sucção de mamadeira, 9,4\% dos pacientes tinham hábito de morder objetos e também $20 \%$ dos pacientes praticavam onicofagia que é o habito de roer as unhas (Tabela 4).

Tabela 4. Frequências absoluta $(\mathrm{N})$ e relativa $(\%)$ referentes aos hábitos bucais deletérios registrados nos prontuários de pacientes pediátricos atendidos em Clínica-Escola. 2018.

\begin{tabular}{lcc|lcrc}
\hline Hábitos bucais deletérios & $\mathrm{N}^{\circ}$ & $(\%)$ & Hábitos bucais deletérios & $\mathrm{N}^{\circ}$ & $(\%)$ \\
\hline Sucção digital & 06 & $(3,3)$ & Morder objeto & 17 & $(9,4)$ \\
\hline Chupeta & 03 & $(1,7)$ & Onicofagia & 36 & $(20,0)$ \\
\hline Mamadeira & 10 & $(5,5)$ & Sem hábitos & 124 & $(68,9)$ \\
\hline Total & 180 & $(100)$ & & 180 & $(100)$ \\
\hline
\end{tabular}

Os hábitos bucais deletérios são um dos maiores fatores etiológicos extrínsecos para o desenvolvimento das más oclusões, pois os mesmos podem influenciar negativamente no desenvolvimento oclusal. São atos que, muitas vezes, são praticados de forma inconsciente, sendo incorporados à personalidade (Pizzol et al., 2012).

A onicofagia, dentre os maus hábitos bucais, acomete não apenas crianças, mas também adultos, e no presente estudo, foi o que mais se destacou, atingindo $20 \%$ das crianças. Segundo a literatura, a onicofagia pode acarretar em diversos males na cavidade bucal, estando associada em alguns casos a tensões. Estes dados também foram observados no estudo de Vasconcelos et al. (2009) onde entre os hábitos bucais deletérios de 970 crianças habitantes da cidade de Recife-PE, 27,8\% dos indivíduos avaliados apresentavam a onicofagia.

O hábito de morder objetos foi o segundo hábito bucal deletério mais prevalente sobre os pacientes pediátricos, incidindo sobre 9,4\% dos indivíduos. No trabalho de Gonçalves et al. (2010), que estudou a relação entre bruxismo, fatores oclusais e hábitos bucais, envolvendo um grupo de 680 estudantes, de ambos os gêneros, assim como no atual estudo o hábito de morder objeto ficou logo após da onicofagia $(30,7 \%)$ atingindo $16 \%$ dos escolares que participaram da pesquisa, seguido pela sucção digital $(4,5 \%)$ e sucção de chupeta $(1,4 \%)$.

$\mathrm{Na}$ atual pesquisa foi possível observar que 5,5\% dos pacientes de pediatria faziam sucção 
de mamadeira. Esse número foi bastante semelhante ao registrado no trabalho de Boeck et al. (2012), em que foi avaliada a prevalência de más oclusões em alunos das escolas municipais de Araraquara-SP, sendo um total de 1.446 estudantes entre 5 a 12 anos de idade, onde registrou que $3,11 \%$ dos escolares apresentavam o hábito de sucção de mamadeira.

Foi verificado que 3,3\% das crianças atendidas apresentavam o hábito de sucção digital. Entretanto Pizzol et al. (2012) relataram em seu estudo com 1.371 estudantes que a prevalência dos hábitos de sucção não nutritiva e sua relação com a idade, gênero e tipo de aleitamento em pré-escolares da cidade de Araraquara-SP, foi de 11\%, um número quase três vezes maior que o presente estudo.

O hábito de sucção nutritiva possui um grande papel para o desenvolvimento orofacial e fisiológico do ser humano no início da vida, entretanto, a persistência deste hábito após este período, é considerado prejudicial para musculatura e os ossos da face, podendo vir a causar más oclusões. Dentre os hábitos de sucção não nutritiva, a chupeta foi a que teve a menor incidência sobre os pacientes pediátricos, apenas $2 \%$ dos indivíduos. E Almeida, Silva e Serpa (2009) estudaram a relação entre má oclusão e hábitos orais em 41 prontuários de pacientes pediátricos da Universidade Federal de Santa Maria (UFSM) e verificaram que a sucção de chupeta atingiu uma porcentagem de $19,51 \%$, enquanto a sucção digital alcançou $17,07 \%$.

Com relação aos hábitos bucais deletérios e gênero no presente estudo registrou-se que estavam presentes em $48 \%$ do sexo masculino e em $41 \%$ do sexo feminino (gráfico 2).

Gráfico 2. Frequência relativa (\%) referentes aos hábitos bucais deletérios conforme o sexo dos nos prontuários de pacientes pediátricos atendidos em Clínica-Escola. 2018.

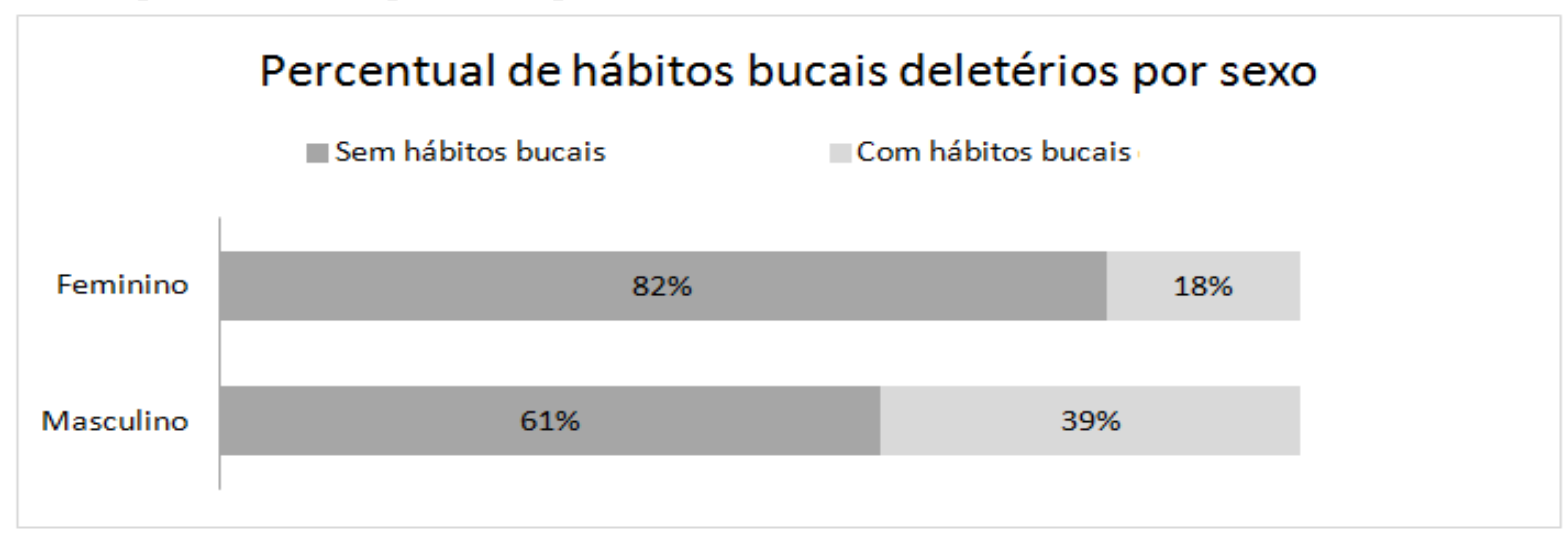


Nota-se também que no presente estudo, os hábitos bucais deletérios estavam mais presentes no sexo masculino, em 39\% dos pacientes. No entanto Vasconcelos et al. (2009) observou que das 970 avaliações em crianças de Recife-PE houve maior presença de hábitos bucais deletérios no sexo feminino.

Foi observado que 36,1\% dos pacientes apresentavam más oclusões anteroposteriores, $13,8 \%$ exibiam más oclusões verticais e $5 \%$ transversais. No estudo notou-se também, que dentre os hábitos bucais deletérios, a onicofagia (20\% dos indivíduos) foi a mais presente.

Apesar das más oclusões apresentam ampla prevalência, é possível que muitos indivíduos não sejam assistidos na infância de maneira correta, acarretando sérios problemas no adulto. Portanto, há necessidade de implementação de ortodontia interceptativa em pacientes pediátricos com más oclusões, e recomenda-se a realização de procedimentos preventivos para evitar o agravo e orientar os indivíduos para que não venham a desenvolver esse problema.

\section{Referências}

Almeida, F. L.; Silva, A. M. T.; Serpa, E.O. (2009). Relação entre má oclusão e hábitos em respiradores orais. Revista Cefac, v. 11, p. 86.

Boeck, M.E.; Pizol, K. E. D. C.; Navarro, N. et al. (2013). Prevalência de mal oclusão em escolares de 5 a 12 anos de rede municipal de ensino de Araraquara. Revista Cefac, v. 15, p. $1270-1280$.

BRASIL - Ministério da Saúde (2012). SB Brasil 2010: Pesquisa Nacional de Saúde Bucal: resultados principais. Brasília.

Domann, J.; Cruz, C. M.; Crepaldi, M. V. et al. (2016). Mordida Aberta Anterior, Etiologia, Diagnóstico e Tratamento Precoce. Revista Faipe, v.2, p. 28-42.

Frazão, M. C. A.; Rodrigues, V. P.; Pereira, A. L. P. (2015). Prevalência das más oclusões em escolares da rede pública no município de São Luís, Maranhão: estudo transversal quantitativo. Revista Pesquisa e Saúde, v. 16, p. 11-15.

Felicio, L. G.; Ruellas, A. C. O.; Bolognese, A. M. et al. (2010). Análise de dentição mista: tomografia versus predição e medida radiográfica. Dental Press Journal of Orthodontics, v. 15, p. $159-165$.

Gonçalves, L. P. V., Toledo, O. A.; Otero, S.A. M. (2010). Relação entre bruxismo, fatores 
oclusais e hábitos bucais. Dental Press Journal of Orthodontics, v.15, p. 97-104.

Guedes-Pinto, A. C. (2010). Odontopediatria. Santos, 970p.

IBGE- Instituto Brasileiro de Geografia e Estatística. (2011). Dados do censo demográfico entre 1940 a 2010.

IBGE - Instituto Brasileiro de Geografia e Estatística. (2017). Estimativa da População 2017.

Martins, J. D.P. Prevalência de má oclusão em pré-escolares no município de Boa Vista-PB. Monografia. UEPB, Paraíba, Brasil, 44p. 2016.

Morais, C.H.; Zanin, L.; Degan, V. V., et al. (2016). Malocclusion in schoolhildren aged 7-12 years old in Minas Gerais, Brazil. Revista Gaúcha de Odontologia, v.64, p.164-170.

Nogueira, J. S. Má oclusão: causas e consequências uma abordagem comparativa. Monografia (Especialização). Universidade Estadual de Campinas, Piracicaba, Brasil, 33p. 2014.

Olguín, V. P. \& Yánez, O. B. R. (2016). Corticotomy: historical perspective. Revista Odonto Mex, v. 20, p. 82-92.

OMS - Organização Mundial da Saúde. (1991). Levantamento epidemiológico básico de saúde bucal.

Piaia, F. N.; Zilio, E. A.; Estery, L. et al. (2016). Prevalência de mordida cruzada posterior em escolares de 6 a 10 anos no município de Vila Maria-RS. Jornal Oral, v. 5, p. 34-39.

Pizzol, K. E. D. C; Montanha, S. S.; Fazan, E. T. et al. (2012). Prevalência dos hábitos de sucção não nutritiva e sua relação com a idade, gênero e tipo de aleitamento em pré-escolares da cidade de Araraquara. Revista Cefac, v. 14, p. 1-10.

Souki, M. Q. (2016). Severe Angle Class III skeletal malocclusion associated to mandibular prognathism: orthodontic-surgical treatment. Dental press journal of orthodontics, v. 21, p. $103-114$

Tomita, N. E.; Bijela, V. T.; Franco, L. J. (2000). Relação entre hábitos bucais e má oclusão em pré-escolares. Revista de Saúde Pública, v. 34, p. 299-303.

Vasconcelos, F. M. N.; Massoni, L. T.; Ferreira, A. C. B. (2009). Ocorrência de Hábitos Bucais Deletérios em Crianças da Região Metropolitana do Recife. Revista Brasileira de Odontopediatria Clínica Integrada, v. 9, p. 327-332.

Vilain, C.T.; Mendes, L.; Simões, P. W. et al. (2016). Prevalência de mal oclusão em crianças de 05 anos de idade em um município catarinense. Revista de Odontologia Universitária, v. 28, p. $210,222$. 